\title{
Globalization Speaks English: The In (visibility) of Algerian Literature and Its Resistance to Translation
}

\author{
Yasmina DJAFRI \\ Department of English Language \\ Faculty of Foreign Languages, Abdelhamid Ibn Badis University \\ Mostaganem, Algeria \\ Soumia OSAMNIA \\ Department of English Language, \\ Faculty of Foreign Languages, Mostapha Stambouli University \\ Mascara, Algeria
}

\begin{abstract}
The urge to adjust curricular and pedagogical contents of what texts of literature teach to learners of a foreign language, notably English, implies an understanding of the concept of global literary canon. Global or world literature then entails a literature that does not abide by the rigidity of the borders, which imprison texts within the local confinements of national identity traits. It is rather a process which allows the circulation of texts across national borders for the purpose of forming one huge hybrid culture that mixes various literary flavors. In an era of globalization and while the very notion of Western canon seems obsolete and out dated, there still exists some sort of discrimination among the texts allowed to enter the global literary canon. Some literary texts are considered not exotic enough or too exotic to meet the expectations of a wide and translational readership. For that reason, a great number of texts is deliberately marginalized and dropped from the canon confirming then the Western monopole operating upon the marketing and publishing houses. In this view of things, the present paper addresses the particular status of the Algerian literature in French within the global literary canon. It, also, aims to analyze its resistance to translation as major obstacle to its circulation and, thus, invisibility.
\end{abstract}

Key words: Algerian literature written in French, in (visibility), literary canon, translation

Cites as: DJAFRI, Y., \& OSAMNIA, S. (2018). Globalization Speaks English: The In (visibility) of Algerian Literature and Its Resistance to Translation. Arab World English Journal for Translation \& Literary Studies, 2 (4),191- 201.

DOI: http://dx.doi.org/10.24093/awejtls/vol2no4.14 